(b) A similar method was adopted in testing Ostwald's claim with regard to the colour-circle. Two concentric circles, of diameters 50 and 52 inches respectively, were drawn on white cardboard, and the ring between them divided into 48 equal parts. From the 24 Ostwald colours pieces were then cut out in the exact shape of the ring-segments, and laid on the ring in such a way that each piece was followed by a blank segment. Twelve subjects were told that the average difference between one colour and the next was represented by one blank space on the chart, and that if anywhere they noted that two colours were either too close together, or too far apart to be fairly represented by a distance of one space, they should change the distance until it represented as accurately as possible their opinion of the difference. The following table gives the average amount of change advocated, indicating both direction and size of the change. A + sign indicates that on Ostwald's circle the distance between the two colours is too small, and should be increased by the amount shown; a - sign indicates that the distance should be diminished by the amount shown.

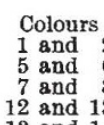

Change
-0.83
-0.58
+0.75
+1.17
+0.17
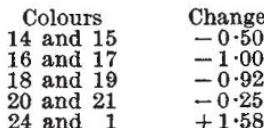

It is clear that in view of these results the validity of Ostwald's claim must be seriously doubted.

(c) For testing Ostwald's third claim, eight grey harmonies were constructed in accordance with his specifications, and eight grey combinations, made up to contravene his principles. The size of the inequality in these combinations varied from 1 to 3 steps. The 16 triads were ranked in order of liking by six subjects, the average intercorrelation between them being $0 \cdot 49$. The average order of these subjects would correlate with the true order of the whole population of which they were only a sample to the extent of approximately 0.92 (footnote 6 , and references); hence we may take their average ranking as a fairly close approximation to the 'true order'. On the average, the harmonies are ranked $8 \cdot 7$, the combinations $8 \cdot 3$; in other words, if anything the combinations are preferred. The best-liked triad is a combination, the least-liked a harmony. This adverse result seems due, however, not so much to any fault in Ostwald's proposed law, as rather to the inaccuracy of the spacing of the greys in his system; introspective evidence shows that the combinations and harmonies most preferred are those in which the differences are seen as equal.

(d) To test Ostwald's last claim, 48 diads were used. There are 24 diads which have a circle distance of 8 steps; in addition 12 diads were included with a circle distunce of 5 steps and another 12 with a cirele distance of 11 steps. Ten subjects arranged these forty-eight diads in order of liking, giving the following average number of points to each group (a scheme of grouping, closely following the normal distribution curve, was adopted in the ranking, as with 48 items the assumption of linearity implicit in the straightforward ranking procedure is likely to be false) :

\section{Circle distance, 5 steps : $3 \cdot 8$ points. Circle distance, 8 steps: 4.5 points. Circle distance, 11 steps : $5 \cdot 2$ points.}

Thus on the average the greater the circle distance, the better liked were the diads. This finding bears out Kirschmann's First Law, namely, that "combinations are pleasant if they yield a maximum . . . contrast effect"?. Additional experiments, involving the ranking of the 24 constituent colours of the diads by the same subjects, also confirm his tenth law, namely, that "the pleasantness or unpleasantness of the single colours affects the pleasantness or unpleasantness of their combinations". The influence of these two factors seems to be about equal, each contributing some 25 per cent to the final ranking.

Thus here also, as in the previous experiments, empirical investigation fails to support Ostwald's claims. In spite of this disappointing conclusion, I believe that the main aims which Ostwald hoped to reach are eminently worth while, and that a repetition of his work with the proper statistical and experimental safeguards would lead to great progress in those applied arts and sciences which to some degree depend on colour, such as art teaching, poster designing and camouflage.

"Ostwald, W., "Colour Science" (London: Windsor and Newton, 1931).

${ }^{2}$ Guild, J., NATURe, 129, 453 (1932).

${ }^{3}$ Barnhart, E. N., J. Exp. P8ychol., 25, 506 (1939).

4 König, A., and Brodhun, E., Akad. Wiss. Berlin, Sitzber., 37, (2), 917 (1888).

' Burkamp, W., Z. Psychol., 55, 2, 133 (1923).

- Eysenck, H. J., J. Exp. Psychol., 25, 650 (1939).

7 Kirschmann, A., Univ. Toronto Stud. Psychol., Series 1, 177-200 $(1900)$.

\title{
CONDENSING PLANT FOR POWER STATIONS
}

$\mathrm{T}$ $\mathrm{HE}$ design of steam condensing plant and associated cooling water systems for power suations was considered from the economic point of view in a paper by W. T. Bottomley (Messrs. Merz and McLellan, consultants) submitted to the North Fast Coast Institution of Engineers and Shipbuilders at Newcastle-upon-Tyne on March 28.

Mr. Bottomley showed that the condensing plant should be designed to fit the circulating-water system, the ratio of the quantity circulating to the tube surface area depending on the length of the water system. Thus for a station close to the bank of a non-tidal river, the ratio should be considerably larger than when tidal water can be utilized. Data are included indicating the performance of the condensers at the Dunston " $B$ " station of the NorthEastern Electric Supply Co., together with the results of cooling tower tests carried out at the Darlington municipal generating station.

Mr. Bottomley's deductions are that the economical water velocity through the tubes, the size of condenser, quantity of water circulating and size of cooling tower can each be determined independently of the others and depend on cost ratios, as does also the economical ratio of water to the surface in the condenser. 
Under dirty conditions, the economical load on a condenser should be about 5,300 B.Th.U. per sq. ft. for base-load stations, instead of the generally recommended figure of 7,000 . When the size of the turbine house building is fixed, it pays to install the largest condenser possible in the space available.

The relation between the normal vacuum in the condenser and the average temperature of the inlet circulating water has been practically fixed by convention. The sizes of condensers built in the United States are much the same as those built in Great Britain, but the quantity of water used is sometimes greater. Port Washington Power Station (U.S.A.) is the most efficient power station in the world. Monthly and yearly average operating figures are published from time to time. In 1937 the average load for the machines was nearly steady at 53,000 kilowatts. The greatest monthly average temperature rise of water, $4 \cdot 2^{\circ} \mathrm{F}$. above that of the circulating water inlet, occurred in March, and the smallest rise, $4.0^{\circ} \mathrm{F}$., occurred in August. The temperature rise of the circulating water of about $4 \cdot 0^{\circ} \mathrm{F}$. shows that the quantity of the circulating water is nearly 250 times the quantity of the steam condensed. It has to be noted that whatever the conventions adopted twenty years ago, prices and conditions have now considerably altered. The most important of these is the average loading of the plant, which, especially in base-load power stations, is considerably higher now than ever before. The cost of fuel per kilowatthour has not materially altered. The fuel consumption per unit has been reduced to a half during the last thirty years. This has been offset to a large extent by the rise in the price of coal, which is now double what it was. When river water is used for cooling, the temperature of the water is the theoretical lower temperature of the cycle; for cooling tower schemes it is the atmospheric wet bulb temperature. In a given locality, these two temperatures on the average are about the same: for example, about $52^{\circ} \mathrm{F}$. in Great Britain.

The approach of the condensing temperature to the theoretical temperature is limited by the question of cost, and the aim of the engineer is to design the plant so that the total annual cost including capital charges is a minimum. Mr. Bottomley shows mathematically that for conditions of minimum cost, the size of the condenser, the size of the tower and the quantity of circulating water can each be determined independently of the others, and this considerably simplifies the problem.

Among the important conclusions deduced is that the effect of deposit on the tubes can only be counteracted by increasing the tube surface and reducing the water velocity. No advantage is gained by increasing the quantity of the circulating water. Bearing in mind the cost of the circulating-water system and the cost of pumping, it is clear that the longer the circulating-water system is, the more the quantity of the circulating water should be reduced and the lower should be the normal vacuum in the condenser. Subject to the ground being suitable to bear the weight, power stations using tidal-river water cooling should be placed as near as possible to the river front, as this reduces the length and cost of the circulating-water system and also improves the overall efficiency of the station. By placing the station on the river front, a saving of about one per cent in the fuel consumption can be effected without reducing the distance between the intake and the discharge to the river, compared with a station placed about $800 \mathrm{ft}$. from the bank.

\section{PLANNING IN GREAT BRITAIN}

\begin{abstract}
A CONFERENCE on National Planning arranged by the Garden Cities and Town Planning Association was held at Oxford on March 28-30. An abstract of the valuable survey presented by Dr. Dudley Stamp at the Conference has already appeared in NATURE of May 24, p. 647. In what follows, digests are presented of some of the other contributions.

Mr. D. E. Gibson's paper on problems of decentralization, central development and satellite towns, while outlining the plans adopted by the Coventry City Council as a basis for Lord Reith's investigation, was essentially a discussion of some of these fundamental problems. It is obvious that we must have an idea of the size of the city for which we are planning before any intelligent planning is possible, and this is true whether of amenity services or of such problems as transport and roads. Such a question can only be answered when national planning arrangements have been made. National planning by the Government, as Mr. Gibson points out, is vital, because such information is required by all planning authorities in the country.

The valuable reports of the Barlow Commission and of PE P (Political and Economic Planning) do not supply all the material that is required as a basis for legislation, though the Conference re-directed attention to them, and Mr. H. W. J. Hick in particular, in his paper on "The Machinery of Planning",
\end{abstract}

urged the adoption of the findings of the Barlow Commission with the reservations and amendments of the signatories of the Minority Report. The field for further investigations, however, is admirably illustrated in some notes for discussion on planning principles by Mr. W. Harding Thompson, which formed one of the most valuable contributions to the Conference.

Mr. Thompson shows that while there may be general agreement as to the objectives of planning, and the argument for decentralization may be regarded as accepted as a basis of policy for the central planning authority, changes occurring during the War must be taken into consideration. Some war fastories may form the nuclei for new industrial settlements, but the central authority must at least provide a general outline plan on very broad lines for national zoning of industry. This plan, moreover, must take account of the balance of community life as well as of other economic and æsthetic factors. Planned redistribution is probably best applied to the numerous light and mobile industries with their wide choice of location.

The unit of regional planning also requires consideration in the light of experience of the civil defence regions. Mr. Thompson throws out as one suggestion the formation of industrial and agricultural planning boards, and stresses the necessity of harmonizing conflicting requirements of various 